\title{
Wind-induced loading and dynamic responses of a row of tall buildings under strong interference
}

\author{
K. M. Lam ${ }^{*}$, J. G. Zhao, M. Y. H. Leung \\ Department of Civil Engineering, The University of Hong Kong, \\ Pokfulam Road, Hong Kong
}

Submitted to: Journal of Wind Engineering and Industrial Aerodynamics

(Revision: January 2011)

Number of pages: $\quad 30$

Number of table: $\quad 2$

Number of figures: $\quad 9$

*Corresponding author:

Dr. K. M. Lam

Department of Civil Engineering, The University of Hong Kong,

Pokfulam Road, Hong Kong

Tel: $\quad$ (852) 28591975

Fax: $\quad$ (852) 25595337

E-mail: kmlam@hku.hk 


\section{Abstract}

This paper studies wind-induced interference effects on a row of five square-plan tall buildings arranged in close proximity. Mean and fluctuating wind loads are measured on each building member and wind-induced dynamic responses of the building are estimated with the high-frequency force-balance technique. The modifications of building responses from interference over a practical range of reduced velocities are represented by an envelope interference factor. Wind tunnel experiments and response analysis are carried out under all possible angles of wind incidence, at four different building separation distances, and for two arrangement patterns of buildings in the row, that is the parallel and diamond patterns. It is found that building interference leads to amplified dynamic responses in many cases but reduction in responses also occurs at some wind incidence. For a building row of the parallel pattern, five distinct wind incidence sectors of different levels and mechanisms of interference effect can be identified. The largest values of envelope interference factors can reach 2.4 for the torsional responses. When the row of tall buildings are arranged in the diamond pattern, increase in wind excitation occurs at many wind angles due to a "wind catchment" effect. The interference factors have larger peak values, reaching 2.1 in the sway directions and above 4 in torsion. However, all large amplifications of building responses do not occur in the situations of peak resonant dynamic responses of the single isolated building. Thus, the design values of peak dynamic responses of a tall building are not significantly magnified when placed in a row.

Key words: Interference effect, dynamic responses, wind tunnel testing 


\section{Introduction}

Interference effects on wind loading of tall buildings have been studied extensively through wind tunnel experiments (Khanduri et al., 1998). Early investigations mostly measured mean wind pressures and wind forces on two interfering building models (Blessmann and Riera, 1979; Saunders and Melbourne, 1979; Hussain and Lee, 1980; English, 1985) with a few studies attempting to measure fluctuating wind loads and building displacements under interference (Bailey and Kwok, 1985; Kareem, 1987; Zhang et al., 1994). With the wide application of the high-frequency force-balance (HFFB) technique for assessment of wind-induced dynamic responses of tall buildings, a number of investigations have been reported on dynamic interference of two buildings placed in all possible relative positions (Khanduri et al., 2000; Xie and Gu, 2005). This enables the determination of interference factors not only for the mean wind loads but also for the dynamic wind loads and even the wind-induced dynamic responses. The interference factor (IF) is commonly defined as the ratio between a wind effect on the building under interference and the wind effect on the building in the isolated single building situation.

In the real built environment, interference effect is seldom limited to two neighbouring tall buildings and with the efficient HFFB technique, studies of interference effects have extended to cases involving more than two buildings. Xie and $\mathrm{Gu}(2004,2007)$ investigated interference effects among three tall buildings in different relative positions. The present authors measured the modifications to mean and fluctuating wind loads when a tall building is placed in a group of same-shaped buildings in the arrangement of a row, a " $\mathrm{L}$ " or a "T" pattern (Lam et al., 2008, Zhao and Lam, 2008).

This paper follows our previous paper (Lam et al., 2008) and reports further wind tunnel testing data and analysis of interference effects in a row of tall buildings. The side-by-side 
arrangement of similar-shaped tall buildings in a row pattern is commonly found in residential developments along the coast or harbor front. The buildings are closely spaced with clear building separations often less than one building width. There are two possible arrangement patterns of buildings in the row: parallel side-by-side pattern and diamond diagonal-by-diagonal pattern. In Lam et al. (2008), we measured mean and dynamic wind loads on five building models in the parallel pattern and at all possible wind incidence angles and for a number of clear building separations. We observed some interference phenomena which have seldom been reported previously. In this paper, we report results of the diamond pattern. Analysis is also made on the wind-induced dynamic deflections of the buildings under interference, in both patterns, using the envelope IF proposed in Xie and Gu (2005).

\section{Experimental Techniques}

Wind tunnel testing of the building models at a target geometric scale of 1:300 was carried out in the boundary layer wind tunnel in the Department of Civil Engineering at the University of Hong Kong. The tunnel had a testing section of $3.0 \mathrm{~m}$ wide and $1.8 \mathrm{~m}$ tall. With triangular spires and $8 \mathrm{~m}$ fetch of floor roughness elements, natural wind of the open land terrain was simulated with wind speed $\bar{U}_{H} \approx 6.5 \mathrm{~m} / \mathrm{s}$ at roof height of the buildings and Reynolds number $\operatorname{Re}=\bar{U}_{H} B / v=4.3 \times 10^{4}$, where $B$ is the breadth of the building models. Profiles of wind characteristics have been presented in Lam et al. (2008).

The row pattern was made up of five identical tall building models of height $H=\underline{0.5}$ $\underline{\mathrm{m}}$, or $150 \mathrm{~m}$ full-scale. All building models had a square plan form at $B=\underline{0.1 \mathrm{~m}}(H / B=5)$. Fig. 1 shows the arrangement of the buildings in the parallel and diamond patterns and the notation of wind load components and wind incidence angle, $\theta$. The building separation 
was defined by the clear building separation $S$ between two adjacent buildings and measurements were made out at four values of $S / B=\{0.5,0.25,0.125,0.1\}$. To cover all building members and all possible wind incidence angles, measurements are made on each of the three buildings, Buildings A, B, C in the parallel pattern and Buildings F, G, H in the diamond pattern, out of the five buildings in a row, and at $10^{\circ}$ intervals between $\theta \in$ $\left[0^{\circ}, 180^{\circ}\right]$

Signals of the fluctuating wind forces and moments at the base of the building models were measured with a six-component force balance (JR3 Inc.). Mean values, root-meansquare (r.m.s.) values of the fluctuations and power spectral density (p.s.d.) of the load components were computed and analyzed. Wind-induced dynamic responses of the buildings were estimated by the HFFB technique (Tschanz, 1982; Tschanz and Davenport, 1983). Measured spectra of the three base moments, $\left(M_{x}, M_{y}, M_{z}\right)$, were combined with the idealized mechanical admittance function of the building to obtain the p.s.d. of the topfloor deflections of the building, respectively, along the $(y, x, \varphi)$ directions. The r.m.s. values of dynamic deflections at the building top floor, deflections $\left(\sigma_{x}, \sigma_{y}, \sigma_{\varphi}\right)$ were obtained from the areas under these spectra which gave the corresponding variances. The mechanical admittance function was assumed from uncoupled linear mode shapes in $x$ or $y$ and a constant mode shape in $\varphi$. The critical damping ratio was set at $\zeta=0.01$ as serviceability of the tall building was the main concern over a large part of the velocity range under study (Lam et al., 2008).

For a tall building, the dynamic deflections are often larger than the mean deflections. In this study, the interference effect on the dynamic building deflections is represented by a dynamic response IF defined by ratios such as:

$$
\mathrm{IF}(\text { dynamic response, } x \text {-direction })=\frac{\sigma_{x}}{\sigma_{x, \text { isolated }}}
$$


This IF quantifies the change to the r.m.s. deflection of the particular building along the $x$ direction from its being in the isolated building situation to its being located in a building row. The same ratio applies to the interference effect on the wind-induced dynamic base moments of the building. An advantage of this dynamic response IF over the IF for mean wind effect is that the denominator seldom has zero or very low values. Assessments of wind-induced dynamic responses have also been carried out at a higher damping ratio of $\zeta=$ $\underline{0.03 \text { and for the building accelerations in addition to deflections. It is found that the IF's are }}$ weakly dependent on the damping ratio or between building deflections and accelerations.

Building responses depend on the incident wind speed and thus the dynamic response IF is a function of the reduced velocity which is defined as:

$$
V_{R}=\bar{U}_{H} /\left(n_{0} B\right)
$$

where $n_{0}$ is the natural frequency of vibration assumed for the particular vibration mode. To simplify the complexity of the problem, Xie and Gu (2007) proposed an envelope interference factor (EIF) which is the maximum value of the IF's within a range of reduced velocity. They used the range of reduced velocity from 2 to 9 and argued that reduced velocities higher than 9 rarely happen for practical structures. In this study, the approach of EIF is adopted. However, Lam et al. (2008) showed that resonant responses occur for the present buildings at reduced velocities around 10 . In order to include these events, the upper limit of the reduced velocity range is raised to 12 in this study. It should, however, be noted that the present assessment of building responses using HFFB and rigid building models could not include the effect of aerodynamic damping which may be critical at the highest reduced velocities.

On the other hand, the reliability of the HFFB technique in assessing building

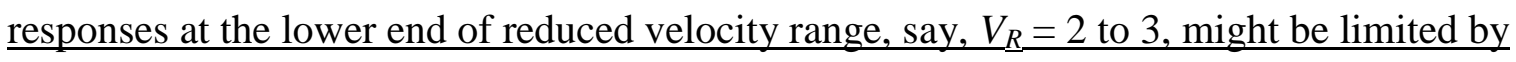
the accuracy of p.s.d. measurement of moments at high frequencies (Judge and Flay, 
2010). Therefore, this study finally adopts the range of $V_{\underline{R}} \in\{5,12\}$ for the computation of EIF such as:

EIF (dynamic response, $y$-direction $)=\max _{V_{R} \in\{5,12\}}\left(\frac{\sigma_{y}}{\sigma_{y, \text { isolated }}}\right)$

For a full-scale $150-\mathrm{m}$ tall, $30-\mathrm{m}$ wide building having a natural frequency at $0.18 \mathrm{~Hz}$ for the sway direction, this range of reduced velocities represents full-scale wind speeds between $\underline{U_{H}}=27 \mathrm{~m} / \mathrm{s}$ and $65 \mathrm{~m} / \mathrm{s}$. In a typhoon-prone region such as Hong Kong, these wind speeds correspond to values at return periods between 1 year and 1000 years (Lam and To, 2009). The EIF in Eq. (3) covers the practical wind speed range for serviceability to ultimate strength situations.

\section{A row of buildings of the parallel pattern}

\subsection{Interference factors for $x$-direction response}

Interference effects of the mean and r.m.s. wind loads, moment spectra and dynamic deflections on Buildings $\mathrm{A}, \mathrm{B}$ and $\mathrm{C}$ in a row of five tall buildings in the parallel pattern have been reported in Lam et al. (2008). For the mean wind loads, sheltering is observed on the inner buildings leading to reduced mean wind loads along the direction of the row, i.e., the $x$ direction, as well as the mean peak torsion. However, increased $x$-direction wind loads are found on the upwind edge buildings and the mechanism for this "upwind interference" phenomenon is explained in details by the pressure distribution on the building faces from wind tunnel measurements and computational fluid dynamics studies. On the other hand, the building responses of $\left(\sigma_{x}, \sigma_{y}, \sigma_{\varphi}\right)$ depend on the r.m.s. values and spectral contents of the 
wind moments. These wind tunnel measurement results were reported in Lam et al. (2008 2009) from which the interference effect was discussed mainly in the qualitative way. In this paper, the interference effect is analyzed quantitatively using the EIF. Fig. 2 shows the EIF for the dynamic deflections of Buildings $\mathrm{A}, \mathrm{B}$ and $\mathrm{C}$ for the three response directions and the four building separations.

Interference effect on the $x$-direction response is discussed first. The EIF for $\sigma_{x}$ in Fig. 2 also apply to the $x$-directional dynamic wind loads of $F_{x}$ and $M_{y}$. For Building A, the variations of EIF with wind angle $\theta$ follows a roughly similar pattern to those of the r.m.s. excitation of the corresponding wind load of $C_{F_{x}}^{\prime}(\theta)$ presented in Lam et al. (2009). For $\theta \leq 60^{\circ}$, the values of EIF are higher than 1 . This is due to the higher value of $C_{F_{x}}^{\prime}$ (and $C_{M_{y}}^{\prime}$ ) as compared with the isolated building. The data of Lam et al. (2008) also show that at $\theta=30^{\circ}$, the normalized p.s.d. of $M_{y}$ on Building A is above that of the isolated single building at all frequencies. This is a result of the upwind interference phenomenon and leads to EIF being higher than 1 . When wind blows at a near normal direction to the building row, vortex-induced excitation occurs on an isolated single building but this is hindered when the building is placed in a row. The associated high r.m.s. peak value and sharp spectral peak in the $x$-direction wind load near $\theta=90^{\circ}$, and the resultant resonant response around $V_{R} \approx 10$, for an isolated single building are no longer there. Thus, it can be observed that EIF for $\sigma_{x}$ drops below 1 as $\theta$ approaches $90^{\circ}$. At $\theta>90^{\circ}$, EIF becomes lower than 1. This is because Building A is being sheltered by the other buildings and under weaker fluctuations of wind excitation along the $x$-direction. Fig. 2 shows that the different values of building separation lead to small changes in EIF for $\sigma_{x}$.

The variations of $\operatorname{EIF}(\theta)$ for $\sigma_{x}$ of Building B are very different from those of Building A. It is noted that at oblique incidence, say $20^{\circ}<\theta<70^{\circ}$, EIF is higher than 1 for 
$S / B=0.5$, while it is lower than 1 for $S / B<0.25$. Spectra of $M_{y}$ excitation on this building at $\theta=0^{\circ}, 30^{\circ}$ and $90^{\circ}$ are shown in Fig. 3. Taking $\theta=30^{\circ}$ to represent an oblique wind incidence, the p.s.d. of $M_{x}$ on Building B at $S / B=0.5$ are above those of the isolated building at all frequencies higher than $n B / \bar{U}_{H}>0.07$. The IF for $\sigma_{\underline{x}} \underline{\text { is thus greater than } 1}$

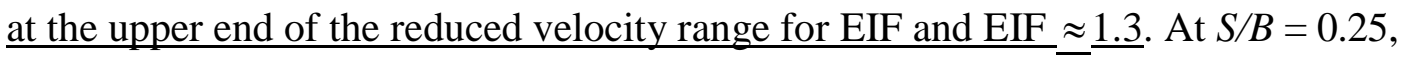
spectral levels of $M_{x}$ are only slightly higher than those of the isolated building at the highest frequencies. The IF at the corresponding reduced velocities are only slightly higher than 1 and EIF $\approx 1.1$ occurs at a low reduced velocity. When $S / B$ becomes smaller than 0.25 , spectral levels of $M_{x}$ at all frequencies are lower than the isolated building case. EIF is thus less than 1. At the oblique wind incidence angle, both $x$-faces of Building B are facing a building gap through which channeled flow occurs. It is conjectured that when the channeled flow passes through a narrow gap, the pressure fluctuations have lower amplitudes. When $S / B>0.25$, some form of building wake effect becomes in action again and the $x$-direction wind loads experience fluctuations more rigorous than the isolated building case.

For Building B, EIF has values higher than 1 at normal incidences, say at $\theta=0^{\circ}$ and $10^{\circ}$ (Fig. 2a). The spectra of $M_{y}$ excitation at $\theta=0^{\circ}$ in Fig. 3 show high frequency excitation on Building B inside a row regardless of the value of $S / B$. This is believed to be caused by the wake effect of the upstream Building A. It should be noted that the reduced $\underline{\text { velocity range between } 5 \text { and } 12 \text { corresponds, respectively, to frequencies }} n B / \bar{U}_{H}=0.2$ and 0.08 , hence EIF is related to the largest ratio of spectral levels of the excitation moment spectra between building under interference and the isolated single building within this frequency range. Therefore, the spectra of $M_{y}$ at $\theta=90^{\circ}$ in Fig. 3 can explain 
why EIF is much below 1 for lateral or near lateral wind incidence to the row ( $\theta$ between $80^{\circ}$ and $\left.100^{\circ}\right)$.

The behavior of $\operatorname{EIF}(\theta)$ for $\sigma_{x}$ of Building $\mathrm{C}$ is very similar to that of Building B and is not discussed further. One notable observation on the curves of $\operatorname{EIF}(\theta)$ for the $x$ direction responses in Fig. 2 is that there exist five distinct wind incidence sectors with different strengths of interference effect as reflected by different ranges of EIF. The wind incidence sectors are named as follows: front and rear incidence to the row, front and rear oblique incidence and lateral incidence. The corresponding ranges of wind angles are listed in Table 1. To investigate the variations of EIF among these wind incidence sectors, a peak EIF (PEIF) is defined for each sector. The PEIF is the maximum value of EIF's over the wind angles within that wind incidence sector.

The uppermost two plots in Fig. 4 show how the PEIF for $\sigma_{x}$ changes with building separation for Buildings A and B. The results for Building $\mathrm{C}$ are similar to Building $\mathrm{B}$ and are thus omitted for brevity. The PEIF data for Building A illustrate clearly the distinct strengths of interference effect at different wind incidence sectors. For all values of $S / B$, PEIF $>1$ for front incidence and front oblique incidence while PMIF $<1$ for the other three wind incidence sectors except one data point. The dependence of PEIF on $S / B$ is not significant for this building. The overall largest value, that is, all-angle maximum, of PEIF is about 1.8 which occurs at front oblique incidence and at $S / B=0.5$. These largest EIF values are summarized in Table 1. For Building B, PEIF higher than 1 occurs for all values of $S / B$ under front incidence and PEIF $<1$ under lateral incidence. For front oblique or rear oblique incidence, PEIF generally increases with $S / B$. PEIF $<1$ at the smallest building separation of $S / B=0.1$ and becomes $>1$ when $S / B>0.125$. For rear incidence, PEIF $\approx 1.1$ for all values of $S / B$. Similar patterns of PEIF are found for Building C. 


\subsection{EIF for $y$ - and $\varphi$-direction responses}

Variations of $\operatorname{EIF}(\theta)$ for $\sigma_{y}$ are shown in the second row of plots in Fig. 2. Compared to $\sigma_{x}$, the ranges of variations are smaller. The effects of $S / B$ are also less significant. The five wind incidence sectors can be used to distinguish roughly the different ranges of EIF. One exception is $\theta=70^{\circ}$ for Building A where large values of EIF are found at $S / B<0.5$.

To help understand the behavior of Building A, excitation spectra of $M_{x}$ are shown in Fig. 5 for $\theta=0^{\circ}, 70^{\circ}$ and $170^{\circ}$. At $\theta=0^{\circ}$, across-wind resonant excitation on the isolated single building cannot occur on Building A. At frequencies $n B / \bar{U}_{H}>0.08$ (corresponding to reduced velocity < 12), spectral levels of $M_{x}$ are all generally lower than the isolated building case. At this wind angle, Building B may be under some form of high-frequency excitations due to the wake of the upstream Building A. These excitations are observed at the high frequency end of $M_{x}$ spectra (not shown). This leads to EIF near 1 for the smaller building separation and EIF $>1$ for $S / B=0.5$ (Fig. 2). As wind veers from the normal incidence, these high-frequency excitations cannot cause coherent forces on this Building B and EIF is noticeably lower than 1. Fig. 5 shows that at $\theta=70^{\circ}$, p.s.d. of $M_{x}$ on Building A are well above the isolated single building except when $S / B=0.5$. This explains the sharp rise of EIF at this angle (Fig. 2). At $\theta=170^{\circ}$, the p.s.d. of $M_{x}$ are lowered largely from the isolated building case with violent across-wind excitation. Thus, EIF is much lower than 1 .

For Building $\mathrm{C}$, curves of $\operatorname{EIF}(\theta)$ for $\sigma_{y}$ are similar to other from Building B. The main difference is that at $\theta=0^{\circ}, \mathrm{EIF}<1$. This may be because Building $\mathrm{C}$ is downstream of two buildings so that the wake disturbances cannot produce coherent forces on it. 
The last row of plots in Fig. 2 shows $\operatorname{EIF}(\theta)$ for the torsional responses. It is observed that EIF changes between above 1 and below 1 when $\theta$ changes across the five wind incidence sectors suggested in Table 1. For instance, EIF for Building C is slightly less than 1 for front incidence and rear incidence. High values of EIF are found at oblique incidence, either front oblique or rear oblique, especially at $S / B=0.5$. At lateral incidence and $S / B \leq 0.25$, very small values of EIF are found.

One general observation on EIF for the torsional responses is that similar degrees of interference effects are found for building torsion when the building separation is smaller than $S / B \leq 0.25$, but when $S / B$ increases to 0.5 , largely magnified torsion occurs, especially on Buildings B and C at oblique incidence. In previous studies on dynamic interference (e.g. Bailey and Kwok, 1985; Zhang et al, 1994) where the building separation is greater than the building breadth, values of IF greater than 1 are found in most cases. An explanation was suggested that increased force fluctuations are always caused by the upstream building and this wake effect increases the dynamic responses of the downwind building. In this study, it appears that the above phenomenon may be responsible for the positive interference effect (EIF $>1$ ) at $S / B=0.5$ (or larger building separation). The separation at $S / B=0.25$ seems to be a switch-over point and it appears that for $S / B \leq 0.25$, the close proximity of the buildings renders the wake effect not effective in producing coherent forces on the downstream buildings.

The switching over of interference effect at $S / B \approx 0.25$ also applies to the EIF for $\sigma_{x}$. For $S / B \leq 0.25, \underline{\text { EIF }<1 \text { generally occurs }}$ on Buildings $\mathrm{B}$ and $\mathrm{C}$ at oblique or lateral incidence. The reduced wind excitation may be caused by, for instance, the fast flow channeled through a narrow gap which is unlikely to produce force fluctuations of large fluctuating amplitudes on the relevant building face (Lam et al., 2008). 


\subsection{EIF in different wind incidence sectors}

The preceding Section 3.1 suggests that interference effects of distinct strengths occur on a number of different wind incidence sectors. The effect of building separation is discussed in the previous section. It is thus worth investigating the variations of PEIF in these sectors with building separation as shown in Fig. 4. The characteristics of PEIF for the $x$-direction responses have been discussed in Section 3.1.

For the torsional responses, the switch-over of suppressing or weak interference (EIF $\leq 1$ or slightly above 1$)$ to strong interference effect at $S / B>0.25$ is evident on the inner building such as Building B. For rear wind incidence to the inner buildings as well as to Building A, PEIF $<1$ is found on $\sigma_{\varphi}$. Suppression of responses with PEIF $<1$ is also observed under lateral incidence to all buildings in the row except at the widest $S / B=0.5$ at which PEIF is very near 1 . Very high values of PEIF $(>2)$ occur for torsion on the edge

Building A at front oblique incidence at all building separations and for the inner buildings at the widest $S / B=0.5$ under front oblique or rear oblique incidence. This may be connected with the upwind interference effect discussed in Lam et al. (2008).

For the $y$-direction response, the building separation $S / B$ has much less significant effect on PEIF. For the inner buildings (such as Building B), PEIF is generally below or slightly higher than 1 . For the edge Building $\mathrm{A}, \mathrm{PEIF} \approx 0.5$ are found at rear incidence at all values of $S / B$. For front oblique incidence, PEIF $=1.55$ at $S / B=0.125$ and when $S / B$ increases further, PEIF reduces and becomes near 1 at $S / B=0.5$. For the other three wind incidence sectors, PEIF have values near 1.

For simple design purposes, Table 1 also lists the maximum value of PEIF over all possible incidence sectors or angles. For the $x$-direction responses, EIF have maximum values between 1.6 and 1.9, approximately, for buildings in a row. The $y$-direction 
responses are along direction perpendicular to the building row and the maximum values of EIF for $\sigma_{y}$ are roughly between 0.8 and 1.2 for all buildings. The exception is Building $\underline{\text { A on which a high value of EIF }=1.55 \text { occurs at front oblique incidence and } S / B=0.125}$. Strong interference leads to large magnifications in the torsional responses, with maximum EIF values ranging between 1.4 and 2.4. For the inner buildings in the row, response magnifications become sharply larger when the building separation increases to $S / B=0.5$.

\subsection{Implications to peak dynamic responses}

The EIF or PEIF is a ratio of dynamic responses between the building under interference and the isolated single building. The condition and wind angle for large dynamic responses of a building under interference requires both a high EIF and large responses of the single building. The variations of EIF with $\theta$ have been shown in Fig. 2 . For the single building, peak responses in the two sway directions are due to across-wind excitation (Lam et al., 2008) and they occur at $\theta=90^{\circ}$ for $\sigma_{x}$ and $\theta=0^{\circ}$ and $180^{\circ}$ for $\sigma_{y}$. Peak values of r.m.s. torsional excitation occur at all normal incidence, that is, $\theta=0^{\circ}, 90^{\circ}$, $180^{\circ}$. It can be observed from Fig. 2 that under these angles of peak responses on the single building, EIF generally have values lower than 1 . These include the following cases on all buildings in a row: $\sigma_{x}$ at $\theta=90^{\circ}$; torsional responses at $\theta=90^{\circ}$ and $180^{\circ}$; and $\sigma_{y}$ at $\theta=180^{\circ}$. EIF of values close to 1 are found for torsion on Buildings A and B at $\theta=0^{\circ}$ and $\sigma_{y}$ on Building A at $\theta=0^{\circ}$. Magnification of actual peak responses only occurs for $\sigma_{y}$ on Building B at $\theta=0^{\circ}$ and the magnification is about 1.8 times regardless of the value of building separation. 
In other words, although dynamic responses are found to be amplified in many cases for tall buildings being placed in a row, this does not usually occur at the wind angles of peak responses. This may have strong implications on the structural and serviceability design of the tall buildings under interference in a row. The present study covers building separation up to $S / B=0.5$. At wider separation, interference effect on the buildings in a row may be similar to that between two tall buildings of which data are available from a number of previous studies (e.g., Khanduri et al., 1998; Xie and Gu, 2005).

\section{A row of buildings of the diamond pattern}

\subsection{Mean wind loads}

Wind load measurements are made on a row of five buildings in the diamond pattern. As shown in Fig. 1b, the wind angle notation is referenced to the direction of the row so that $\theta=45^{\circ}$ and $135^{\circ}$ correspond to wind incidence normal to the building faces. Fig. 6 presents the results of mean force and torsion coefficients, $\bar{C}_{F_{x}}, \bar{C}_{F_{y}}$ and $\bar{C}_{M_{z}}$, on the edge Building $\mathrm{F}$ and the inner Buildings $\mathrm{G}$ and $\mathrm{H}$. Due to the definition of wind angle to the building body axes, the wind angle variations of these coefficients on an isolated single building are those of the parallel arrangement (in Lam et al., 2008) shifted by $45^{\circ}$. The moment coefficients of $M_{x}$ and $M_{y}$ follows similar wind angle variations as $-F_{y}(\theta)$ and $F_{x}(\theta)$, respectively and are not shown for brevity.

The most obvious observation in Fig. 6 is that at many wind angles, the inner Buildings $\mathrm{G}$ and $\mathrm{H}$ experience significantly increased shear forces (and overturning moments) from the single isolated building situation, especially along the $+x$ and $+y$ directions. The edge 
Building $\mathrm{F}$ also experiences increased wind forces but over a smaller range of wind angles and with smaller levels of increase. This is very different from the observations on the parallel arrangement in which wind loads on the inner buildings are largely reduced due to sheltering (Lam et al., 2008).

When the row of buildings are placed in the diamond pattern, sheltering offered by an upstream building to protect a downstream buildings is not as effective as the side-by-side pattern. Instead, walls of two adjacent buildings forms a corner which catches approaching wind, resulting in stagnation effect and increased positive pressures on the walls concerned. This mechanism explains the increase of $\bar{C}_{F_{x}}$ on Buildings $\mathrm{G}$ and $\mathrm{H}$ (from the single building case) at wind angles $45^{\circ} \leq \theta \leq 135^{\circ}$. At these wind angles, wind blows into the corners of adjacent buildings on the lower part of Fig. 1b. Increased positive pressure is thus produced on the building walls on the lower part of the row. This increases $F_{x}$ in the $+x$ direction. By the same mechanism, the increase in pressure also leads to increase in $F_{y}$ in the +y direction. This "wind catchment" effect is observed on $\bar{C}_{F_{y}}(\theta)$ over the wind angle range of $45^{\circ} \leq \theta \leq$ $135^{\circ}$.

The pattern of $\bar{C}_{F_{y}}(\theta)$ also shows that all buildings have much reduced $y$-direction loads at $135^{\circ} \leq \theta \leq 180^{\circ}$. For the single building at these wind angles, wind blows onto the windward $y$-face and leads to large $F_{y}$. With buildings arranged in the row of Fig. 1b, wind cannot hit directly on these lower $y$-faces at these wind angles, thus reducing the positive pressure on these faces and the resulting $F_{y}$. The third observation is that at $\theta$ between $0^{\circ}$ and $45^{\circ}, \bar{C}_{F_{y}}$ on the inner Buildings $\mathrm{G}$ and $\mathrm{H}$ is positive instead of negative on the isolated single building. This is believed to be caused by the flow sheltering offered by the upstream Building F so both $y$-faces of an inner building are under negative pressure but with the oblique wind incidence, the lower face (in Fig. 1b) has less negative pressure. At wind angle 
close to $45^{\circ}$, negative $\bar{C}_{F_{y}}$ still occur on these buildings at the widest building separation of $S / B=0.5$. Similar interference effects are observed on the $x$-direction loads at $\theta$ between $135^{\circ}$ and $180^{\circ}$.

The wind catchment effect occurs on the recessed corners formed by walls of two adjacent buildings. Thus, effects of the same degree are expected on Buildings $\mathrm{G}$ and $\mathrm{H}$. They are also under the same degree of the wake effect just described. This explains why $\bar{C}_{F_{x}}(\theta)$ and $\bar{C}_{F_{y}}(\theta)$, as well as the wind torsion, on the two inner buildings are almost identical (Fig. 6).

For the edge Building $\mathrm{F}$ under wind incidence at $45^{\circ} \leq \theta \leq 135^{\circ}$, the wind catchment effect cannot occur on the windward $x$-wall of Building F so that there is no increase in $\bar{C}_{F_{x}}$ at these wind angles. However, $\bar{C}_{F_{x}}$ is slightly higher than the single building value at some wind angles around $45^{\circ}$. This may be caused by the channeled flow past the building gap with Building $\mathrm{G}$ which produces more negative pressure on the leeward $x$-wall.

For torsion, Building $\mathrm{F}$ has reduced peak values of $\bar{C}_{M_{z}}$ than the single building. On the contrary, peak torsions on the inner buildings are slightly higher than those on the single isolated building. The pattern of $\bar{C}_{M_{z}}(\theta)$ is also observed to change from a two-period fluctuation within $0^{\circ} \in\left[0^{\circ}, 180^{\circ}\right]$ to a one-period cycle.

The effect of building separation is not obvious in Fig. 6 within the four values of $S / B$ studied, $S / B$ between 0.1 and 0.5 . As discussed in some cases, the widest building separation at $S / B=0.5$ leads to slightly different interference effect but mainly on the degree of the effect. This is different from the case of a row of buildings in the parallel pattern when there appears a main switching over of some interference mechanisms when the building separation increases to $S / B=0.5$. 


\subsection{Fluctuating wind loads}

Fig. 7 shows the r.m.s. wind loads on Buildings $F, G$ and $\mathrm{H}$ under interference. These r.m.s. loads represent fluctuations of wind excitation only and do not include the dynamic magnification as a result of wind-induced vibration of the buildings. On the isolated single building, peak wind load fluctuations are due to across-wind excitation related to vortex shedding. Under the notation of wind angles in Fig. 1b, peak r.m.s. load occurs on $C_{F_{z}}^{\prime}$ at $\theta \approx$ $135^{\circ}$ and on $C_{F_{y}}^{\prime}$ at $\theta$ around $45^{\circ}$. For Buildings $\mathrm{F}, \mathrm{G}, \mathrm{H}$ placed in a row, these peak r.m.s. wind loads are found to disappear or largely weakened in most cases. Instead, lower peaks of $C_{F_{x}}^{\prime}$ and $C_{F_{y}}^{\prime}$ are found at wind angles near to $\theta \approx 90^{\circ}$ and mainly at $S / B=0.25$ only. It seems that at this wind incidence normal to the row of buildings and at this separation, some forms of across-wind excitation may be in action on the diamond cross section. This across-wind effect leads to large wind load fluctuations with components in both the $x$ and $y$ directions. The r.m.s. torsion coefficients on the inner buildings are higher than the isolated single building value at many wind angles, most notably near $\theta \approx 90^{\circ}$.

The moment spectra on the single isolated building show the across-wind vortex excitation peak at $n B / \bar{U}_{H} \approx 0.1$ at normal incidence, that is $\theta$ near to $45^{\circ}$ or $135^{\circ}$. An inspection on the moment spectra on Buildings $F, G$ and $H$ shows that spectral peaks of wind excitation are absent under these wind incidences, as well as in most other cases. However, in many cases, the broad-band spectral levels on the buildings under interference are above those of the isolated building situation. The increase in the broad-band wind excitation is particularly strong at $\theta \approx 90^{\circ}$. This is shown by the examples of moment spectra on Building $\mathrm{H}$ at $\theta=90^{\circ}$. In particular, the broad-band p.s.d. of wind torsion are increased by many times from the single building case, except at the widest building separation of $S / B=0.5$. The same 
particular results at this building separation are also observed in Fig. 7 on the r.m.s. wind loads.

The changes in r.m.s. values and spectral contents of the wind moments due to building interference lead to modifications of the wind-induced dynamic responses of the buildings. In the next section, the EIF proposed in Eq. (3) is used to quantify this aspect of building interference.

\subsection{EIF for building responses}

Similar to the row of building in the parallel pattern, wind-induced dynamic responses are estimated for a group of buildings in the diamond pattern. The EIF analysis is made and the results are shown in Fig. 9 for Buildings F, G and H. When compared to Fig. 2 for the parallel pattern, a number of main differences are observed. One is the pattern of $\operatorname{EIF}(\theta)$ on the edge Building $\mathrm{F}$ is not very different to those on the inner Building $\mathrm{G}$ or $\mathrm{H}$. The next observation is the much higher values of EIF for the diamond pattern. On all buildings and all building separation, EIF is higher than 1 at almost all wind angles other than incidence normal or nearly normal to the building faces at which across-wind vortex excitation occurs in the absence of building interference. The exception wind angles at which EIF $<1$ are $\theta$ around $135^{\circ}$ for the $x$-direction response, $\theta$ around $45^{\circ}$ for the $y$-direction response, and $\theta$ near these two angles for the torsional response.

The distinct wind incidence sectors identified for the EIF for the row of buildings in the parallel patterns (Fig. 4 and Table 1) do not apply to the results in Fig. 9 for the building row of the diamond pattern. The wind incidence cases for particular ranges of EIF are simpler. For wind incidence normal to the building faces, EIF $<1$ for torsion and the corresponding 
responses in the across-wind direction. At other wind angles, EIF $>1$ is caused by the

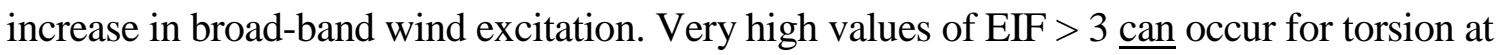
$\theta \approx 90^{\circ}$. For simplified design purposes, the all-angle largest EIF values (PEIF) on different building members and at the four values of building separation are summarized in Table 2.

It can be observed from Table 2 and Fig. 9 that the effect of building separation on EIF in the diamond pattern is not as significant as the parallel pattern. This may be because buildings in the diamond arrangement are already offset from one another and it is not possible to have a long building gap between two parallel building walls. Bailey and $\underline{\text { Kwok (1985) studied interference effect on r.m.s. overturning moments between two }}$ square tall buildings using aeroelastic wind tunnel models. Strong magnifications of both along-wind and across-wind moments were observed on a tall building when the other building is located at a very close upstream staggered location. That arrangement of two buildings is similar to the present diamond pattern. Fig. 9 shows that at $\theta \approx 45^{\circ}$, high values of EIF occur on the present upstream Building $\mathrm{F}$ for the along-wind responses $\sigma_{x}$ (as consistent with the results of Bailey and Kwok (1985)) but EIF $<1$ for the across-wind responses. Bailey and Kwok (1985) suggested that the excitation magnifications were caused by an instability which appeared to be strongly velocity dependent. It may be that the magnifications were highly sensitive on the relative locations of the two buildings or that the instability was dependent on the dynamic changes of the building gap size with the movements of building models (Lam and To, 2003) which are not possible for the present HFFB models.

Table 2 also lists the largest all-angle PEIF among the four values of $S / B$. These maximum PEIF for the $x$ - and $y$-direction building responses have values around 2 for 
buildings in a row. The maximum PEIF for the torsional response is about 3 for the edge Building $\mathrm{F}$ and can reach values at 3.5 or above for the inner buildings.

The actual levels of amplified building responses of tall buildings in a row depend on both the EIF and the responses of the isolated single building. The highest PEIF in Fig. 9 occur at wind angles of generally weaker or weakest r.m.s. responses of the single building (Fig. 7). This means that the resulting dynamic responses of a building placed in a row and under interference may not be very much larger than the single isolated building situation.

\section{Conclusions}

This paper investigates wind-induced interference on a row of five tall buildings arranged in either the parallel or the diamond pattern. In addition to interference effects on the mean and fluctuating excitation wind loads, interference effects on the wind-induced dynamic responses of the tall buildings are studied. As the dynamic responses depend on the reduced velocity, the envelope interference factor (EIF) is adopted to quantify the corresponding interference effects. In this study, this is taken as the maximum value of the IF on the standard deviation of building responses over the range of reduced velocities between 5 and 12. Wind tunnel experiments and response analysis are carried out for three building members in the row at all possible wind incidence angles and at four values of building separation.

Interference mechanisms occurring on buildings placed in a row of the parallel pattern have been discussed in a previous paper. The analysis of EIF in this paper shows that different ranges of EIF can be identified at five distinct wind incidence sectors. This is 
suggested to be caused by the corresponding interference mechanisms such as upwind interference and flow channeling. The peak EIF (PEIF) can be used as a rough simple indicator for the maximum interference effects for design purposes. For the building row of the parallel pattern, the all-angle PEIF in the translational directions generally has values not higher than 2 . The PEIF for the torsional responses are higher and can reach values as high as 2.4. The effect of building separation on PEIF is not very significant when $S / B$ is not wider than 0.25 but PEIF increases sharply when $S / B$ increases to 0.5 . There appears to be a switching over of the magnitudes (and mechanisms) of interference effects at this building separation of buildings in the parallel pattern.

When the row of tall buildings are arranged in the diamond pattern, the interference effect of wind catchment is found to result in significant magnification of mean wind loads at a majority of wind angles. This is caused by the increase in positive pressure when wind flow is caught inside the corners formed by the closest walls of two adjacent buildings. Fluctuating wind loads also become larger over a broad band of frequencies but the spectral peak corresponding to across-wind excitation on the single isolated building is absent. These characteristics of the fluctuating wind excitation lead to EIF $>1$ at all wind angles except incidence normal to the building faces. The wind incidence sectors identified for the building row of the parallel pattern do not apply to the row of the diamond pattern for which the all-angle PEIF have higher values, reaching 2.1 for responses in the translational directions. In torsion, the PEIF can even reach values higher than 4.

Under wind-induced interference, the levels of amplified building responses depend on the combination of EIF and responses of the isolated single building. For the building row of the parallel or diamond pattern, it is found that the largest EIF generally occur at the wind angles at which the single building is under weak dynamic responses. This 
implies that for simple design purposes, the actual magnification of peak design dynamic responses of a tall building being located in a row is not much higher than unity. This and other results of this study can provide relevant information to the design of residential developments in large metropolitan cities.

\section{Acknowledgment}

The investigation is supported by a research grant (HKU7014/02E) awarded by the Research Grants Council of Hong Kong. 


\section{References}

Bailey, P.A., Kwok, K.C.S., 1985. Interference excitation of twin tall buildings. J. Wind Eng. Ind. Aerodyn. 21, 323-338.

Blessmann, J., Riera, J.D., 1979. Interaction effects in neighbouring tall buildings, In: Proc. 5th Int. Conf. Wind Engng, Colorado State Univ., Fort Collins, Colo., 381-395.

English, E.C., 1985. Shielding factors from wind-tunnel studies of mid-rise and high-rise structures, In: Proc. 5th US Nat. Conf. Wind Engng, Texas Tech Univ., Lubbock, Texas, 4A, 49-56.

Hussain, H., Lee, B.E., 1980. A wind tunnel study of the mean pressure forces acting on a large group of low-rise buildings. J. Wind Eng. Ind. Aerodyn. 31, 41-66.

Judge, A.R., Flay, R.G.J., 2010. Wind tunnel investigation of crosswind generalized force spectra for slender shapes. Proc. 14th Australasian Wind Engineering Society Workshop, Canberra, August 2010.

Kareem, A. 1987. The effects of aerodynamic interference on the dynamic response of prismatic structures. J. Wind Eng. Ind. Aerodyn. 25, 365-372.

Khanduri, A.C., Stathopoulos, T., Bedard, C., 1998. Wind-induced interference effects on buildings - A review of the state-of-art. Eng. Struct. 20(7), 617-630.

Khanduri, A.C., Stathopoulos, T., Bedard, C., 2000. Generalization of wind-induced interference effects for two buildings. Wind Struct. 3, 255-266.

Lam, K.M., Leung, M.Y.H., Zhao, J.G., 2008. Interference effects on wind loading of a row of closely spaced tall buildings. J. Wind Eng. Ind. Aerodyn. 96, 562-583. 
Lam, K.M., Leung, M.Y.H., Zhao, J.G., 2009. Erratum to "Interference effects on wind loading of a row of closely spaced tall buildings”. J. Wind Eng. Ind. Aerodyn. 97, 110.

Lam, K.M., To, A.P., 2003. Interference effect of an upstream larger cylinder on the lockin vibration of a flexibly-mounted circular cylinder. J. Fluids Struct. 17(8), 10591078.

Lam, K.M., To, A.P., 2009. Statistical analysis of extreme wind speeds in Hong Kong and Macau. Transactions Hong Kong Institution of Engineers, 16(1), 1-8.

Saunders, J.W., Melbourne, W.H., 1979. Buffeting effects of upwind buildings, In: Proc. 5th Int. Conf. Wind Engng, Colorado State Univ., Fort Collins, Colo., 593-605.

Tschanz, A., 1982. Measurement of total dynamic loads using elastic models with high natural frequencies, In: Workshop on Wind Tunnel Modeling Criteria and Effects, N.B.S., Gaithersburg, Mass., 1982.

Tschanz, A., Davenport, A.G., 1983. The base balance technique for the determination of dynamic wind loads. J. Wind Eng. Ind. Aerodyn. 13, 429-439.

Xie, Z.N., Gu, M., 2004. "Mean interference effects among tall buildings. Eng. Struct. 26, 1173-1183.

Xie, Z.N., Gu, M., 2005. A correlation-based analysis on wind-induced dynamic interference effects between two tall buildings. Wind and Struct. 8, 163-178.

Xie, Z.N., Gu, M., 2007. Simplified evaluation of wind-induced interference effects among three tall buildings. J. Wind Eng. Ind. Aerodyn. 95, 31-52.

Zhang, W.J., Kwok, K.C.S., Xu, Y.L., 1994. Aeroelastic torsional behaviour of tall buildings in wakes, J. Wind Eng. Ind. Aerodyn. 51, 229-248. 
Zhao, J.G., Lam, K.M., 2008. Interference effects in a group of tall buildings closely arranged in an L- or T-shaped pattern. Wind Struct. 11, 1-18. 
Table 1.

Peak envelope interference factors (PEIF) in five wind incidence sectors on tall buildings in a row of the parallel pattern.

\begin{tabular}{|c|c|c|c|c|c|c|c|}
\hline \multirow{3}{*}{$\begin{array}{l}\text { Building } \\
\text { /Response }\end{array}$} & \multirow{3}{*}{$S / B$} & \multicolumn{5}{|c|}{ Wind incidence sectors : $\theta \in[]$} & \multirow{3}{*}{$\begin{array}{l}\text { All-angle } \\
\text { maximum }\end{array}$} \\
\hline & & Front & $\begin{array}{c}\text { Front } \\
\text { oblique }\end{array}$ & Lateral & $\begin{array}{c}\text { Rear } \\
\text { oblique }\end{array}$ & Rear & \\
\hline & & $\begin{array}{l}{\left[0^{\circ},\right.} \\
\left.10^{\circ}\right]\end{array}$ & $\begin{array}{l}{\left[20^{\circ},\right.} \\
\left.70^{\circ}\right]\end{array}$ & $\begin{array}{l}{\left[80^{\circ},\right.} \\
\left.100^{\circ}\right]\end{array}$ & $\begin{array}{c}{\left[110^{\circ},\right.} \\
\left.160^{\circ}\right]\end{array}$ & $\begin{array}{l}{\left[170^{\circ},\right.} \\
\left.180^{\circ}\right]\end{array}$ & \\
\hline \multirow[t]{2}{*}{$\mathrm{A} / \sigma_{x}$} & $\leq 0.25$ & 1.46 & 1.61 & 0.89 & 0.74 & 0.74 & 1.61 \\
\hline & 0.5 & 1.43 & 1.80 & 1.05 & 0.89 & 0.64 & 1.80 \\
\hline \multirow[t]{2}{*}{$\sigma_{y}$} & $\leq 0.25$ & 1.05 & 1.55 & 1.18 & 0.91 & 0.56 & 1.55 \\
\hline & 0.5 & 1.02 & 0.94 & 1.09 & 0.90 & 0.48 & 1.09 \\
\hline \multirow[t]{2}{*}{$\sigma_{\varphi}$} & $\leq 0.25$ & 1.10 & 2.42 & 0.81 & 1.34 & 0.44 & 2.42 \\
\hline & 0.5 & 0.96 & 2.26 & 0.98 & 1.79 & 0.52 & 2.26 \\
\hline \multirow[t]{2}{*}{$\mathrm{B} / \sigma_{x}$} & $\leq 0.25$ & 1.91 & 1.13 & 0.42 & 1.16 & 1.14 & 1.91 \\
\hline & 0.5 & 1.82 & 1.51 & 0.76 & 1.67 & 1.02 & 1.82 \\
\hline \multirow[t]{2}{*}{$\sigma_{y}$} & $\leq 0.25$ & 1.18 & 0.82 & 0.86 & 0.78 & 0.60 & 1.18 \\
\hline & 0.5 & 1.18 & 0.81 & 0.68 & 0.90 & 0.57 & 1.18 \\
\hline \multirow[t]{2}{*}{$\sigma_{\varphi}$} & $\leq 0.25$ & 1.25 & 1.38 & 0.49 & 1.52 & 0.69 & 1.52 \\
\hline & 0.5 & 1.25 & 2.21 & 0.98 & 2.36 & 0.58 & 2.36 \\
\hline \multirow[t]{2}{*}{$\mathrm{C} / \sigma_{x}$} & $\leq 0.25$ & 1.62 & 1.21 & 0.37 & 1.51 & 1.49 & 1.62 \\
\hline & 0.5 & 1.53 & 1.65 & 0.69 & 1.63 & 1.33 & 1.65 \\
\hline \multirow[t]{2}{*}{$\sigma_{y}$} & $\leq 0.25$ & 0.77 & 0.75 & 0.74 & 0.75 & 0.76 & 0.77 \\
\hline & 0.5 & 0.82 & 0.76 & 0.69 & 0.78 & 0.81 & 0.82 \\
\hline \multirow[t]{2}{*}{$\sigma_{\varphi}$} & $\leq 0.25$ & 0.68 & 1.39 & 0.42 & 1.44 & 0.73 & 1.44 \\
\hline & 0.5 & 0.73 & 2.19 & 0.96 & 2.20 & 0.62 & 2.20 \\
\hline
\end{tabular}


Table 2.

Peak envelope interference factors (PEIF) on tall buildings in a row of the diamond pattern, maximum over all wind angles.

\begin{tabular}{|c|c|c|c|c|c|c|}
\hline \multirow{3}{*}{ Building } & \multirow{2}{*}{$\begin{array}{c}\text { Response } \\
\text { direction }\end{array}$} & \multicolumn{5}{|c|}{ PEIF } \\
\cline { 3 - 7 } & & $S / B=0.5$ & $S / B=0.25$ & $S / B=0.125$ & $S / B=0.1$ & $\begin{array}{c}\text { All } \\
\text { separation }\end{array}$ \\
\hline \multirow{3}{*}{$\mathrm{F}$} & $y$ & 2.01 & 1.93 & 1.99 & 1.93 & 2.01 \\
\cline { 2 - 7 } & torsional & 1.97 & 3.04 & 2.77 & 2.64 & 3.04 \\
\cline { 2 - 7 } $\mathrm{G}$ & $x$ & 1.97 & 1.79 & 1.53 & 1.50 & 1.97 \\
\cline { 2 - 7 } & $y$ & 2.05 & 1.74 & 1.40 & 1.41 & 2.05 \\
\cline { 2 - 7 } & torsional & 3.30 & 3.50 & 3.17 & 2.95 & 3.50 \\
\hline \multirow{3}{*}{$\mathrm{H}$} & $x$ & 2.13 & 1.89 & 1.88 & 1.85 & 2.13 \\
\cline { 2 - 7 } & $y$ & 1.90 & 1.95 & 1.87 & 1.67 & 1.95 \\
\cline { 2 - 7 } & torsional & 2.23 & 2.43 & 4.18 & 2.65 & 4.18 \\
\hline
\end{tabular}




\section{Figure legends}

Fig. 1. Wind loads and wind direction convention for a row of tall buildings: (a) parallel pattern; (b) diamond pattern.

Fig. 2. Envelope interference factors (EIF) for the building row of the parallel pattern: variation with wind angles and effects of building separation: (a) Building A; (b) Building B; (c) Building C.

Fig. 3. Wind moment spectra of $M_{y}$ on Building B at three selected wind angles, $\theta$. (a) $0^{\circ}$; (b) $30^{\circ}$; (c) $90^{\circ}$.

Fig. 4. Peak EIF within different wind incidence sectors: variation with building separation: (a) Building A; (b) Building B.

Fig. 5. Moment spectra of $M_{x}$ on Building A at $\theta$. (a) $0^{\circ}$; (b) $70^{\circ}$; (c) $170^{\circ}$.

Fig. 6. Mean wind load coefficients: variation with wind angles and effects of building separation: (a) Building F; (b) Building G; (c) Building H.

Fig. 7. Fluctuating wind excitation: r.m.s. wind load coefficients: (a) Building F; (b) Building G; (c) Building H.

Fig. 8. Moment spectra on Building $\mathrm{H}$ at $\theta=90^{\circ}$. (a) $M_{x}$; (b) $M_{y}$; (c) $M_{z}$. 
Fig. 9. Envelope interference factors (EIF) for the building row of the diamond pattern:

(a) Building F; (b) Building G; (c) Building $\mathrm{H}$. 

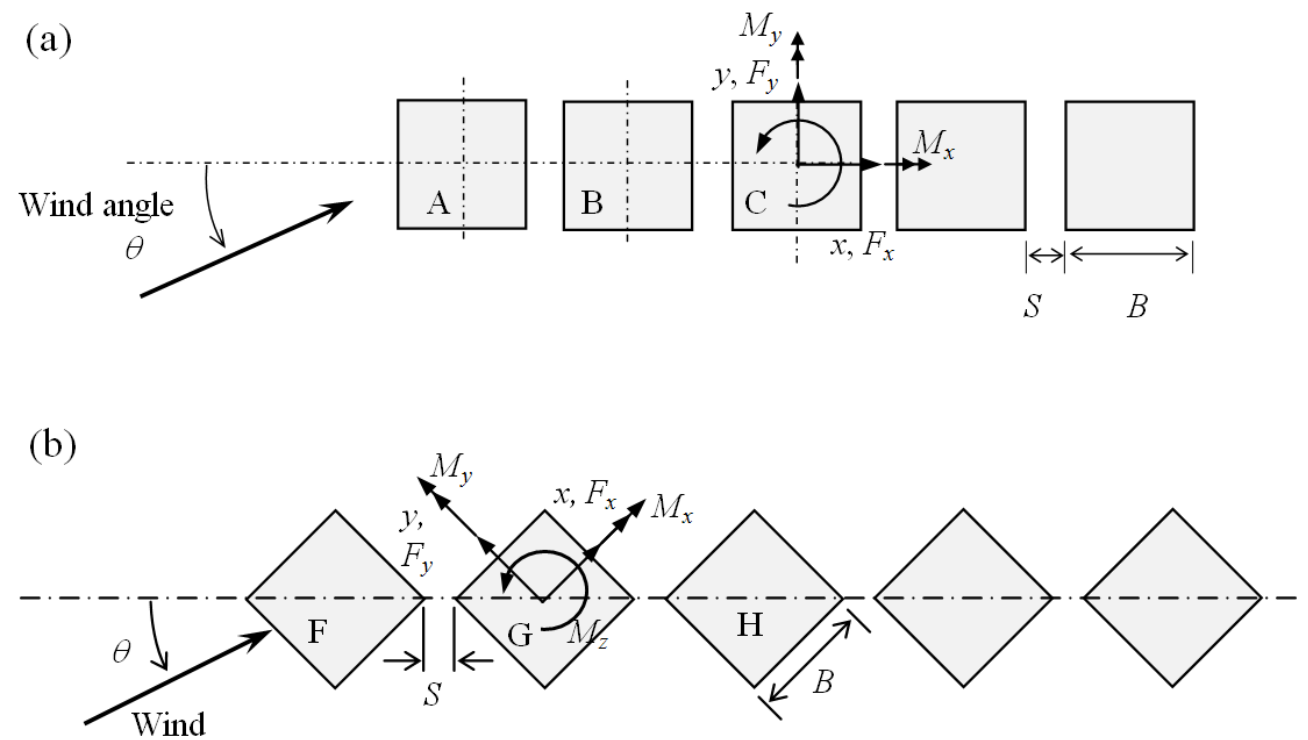

Fig. 1. Wind loads and wind direction convention for a row of tall buildings: (a) parallel pattern; (b) diamond pattern. 


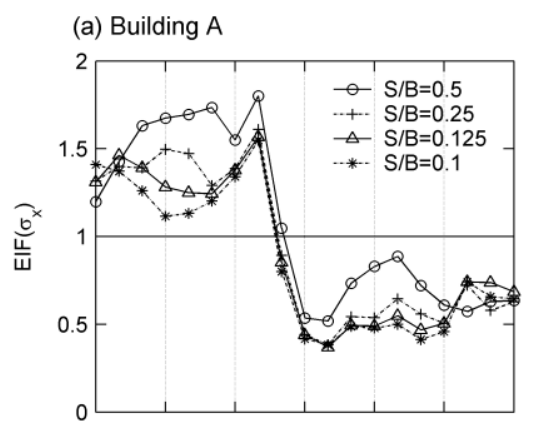

(b) Building B
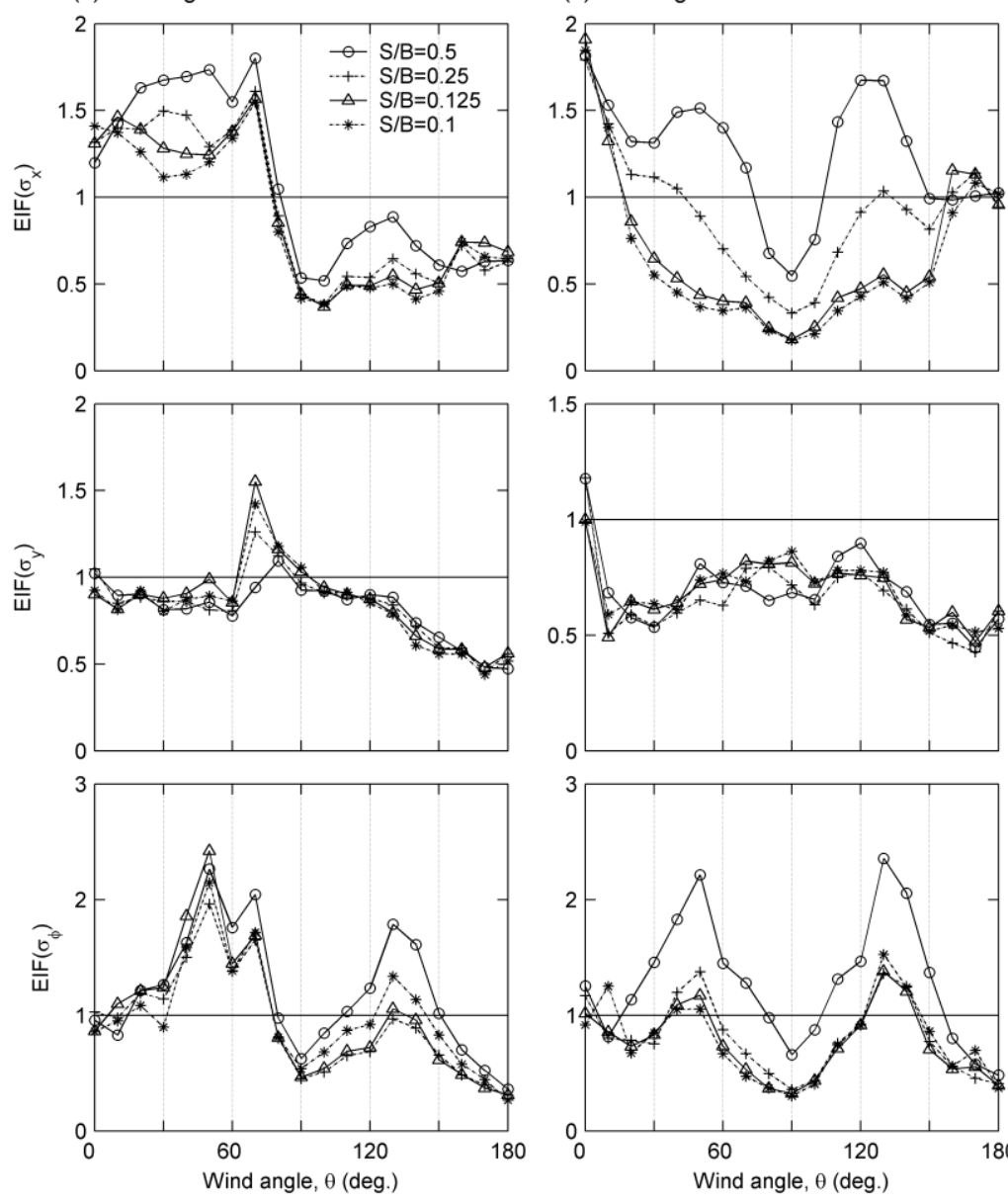
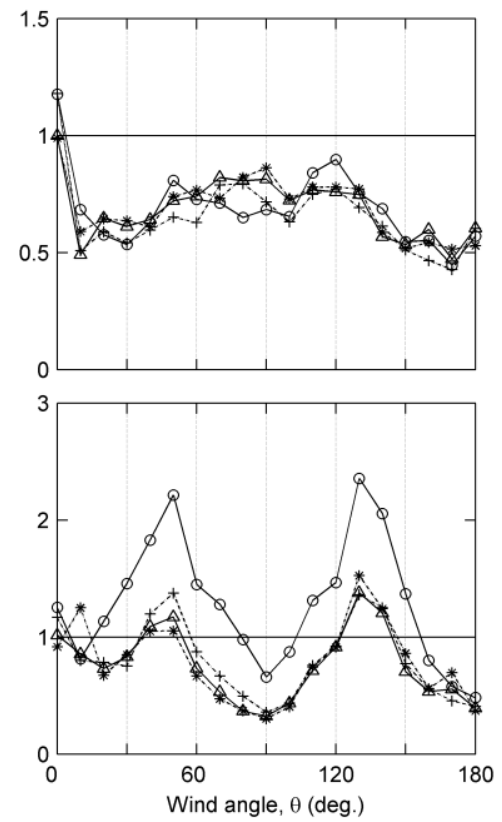

(c) Building C
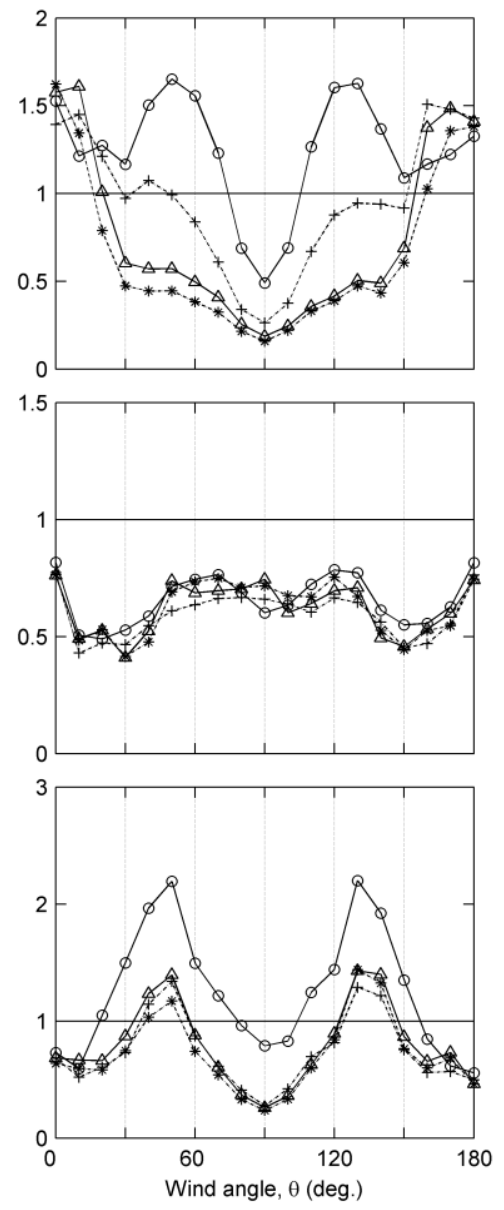

Fig. 2. Envelope interference factors (EIF) for the building row of the parallel pattern: variation with wind angles and effects of building separation: (a) Building A; (b) Building B; (c) Building C. 

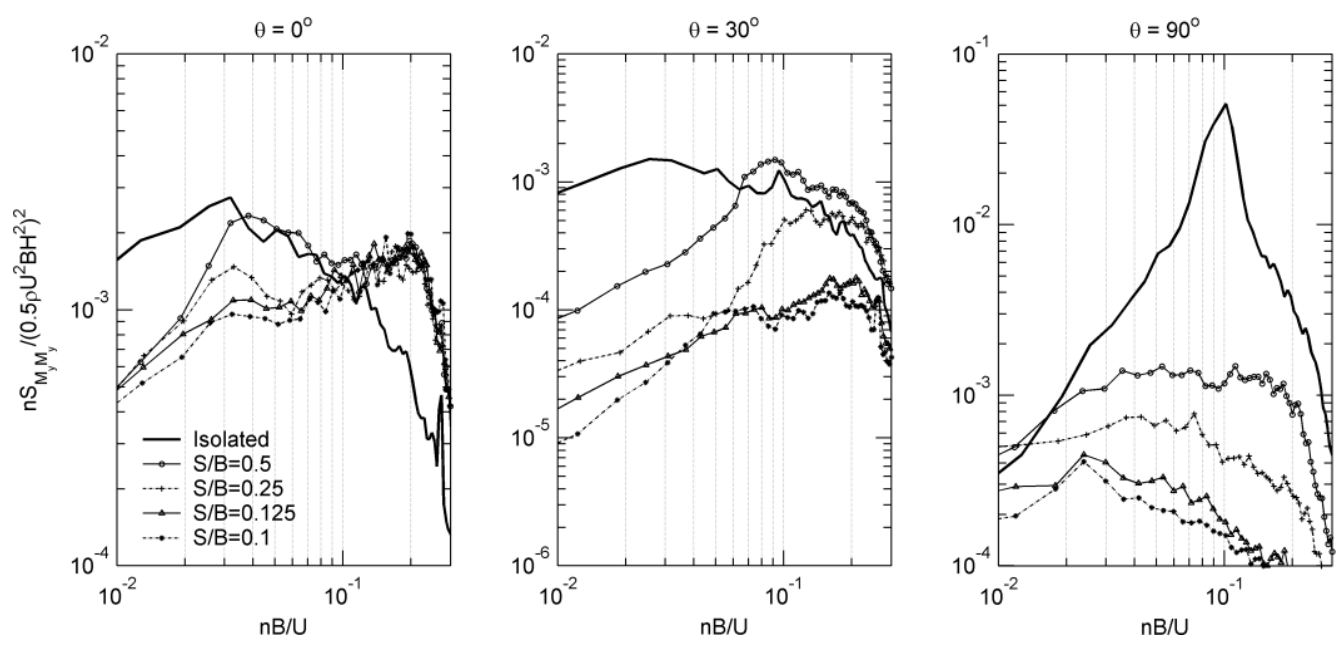

Fig. 3. Wind moment spectra of $M_{y}$ on Building B at three selected wind angles, $\theta$. (a) $0^{\circ}$; (b) $30^{\circ}$; (c) $90^{\circ}$. 
(a) Building $\mathrm{A}$
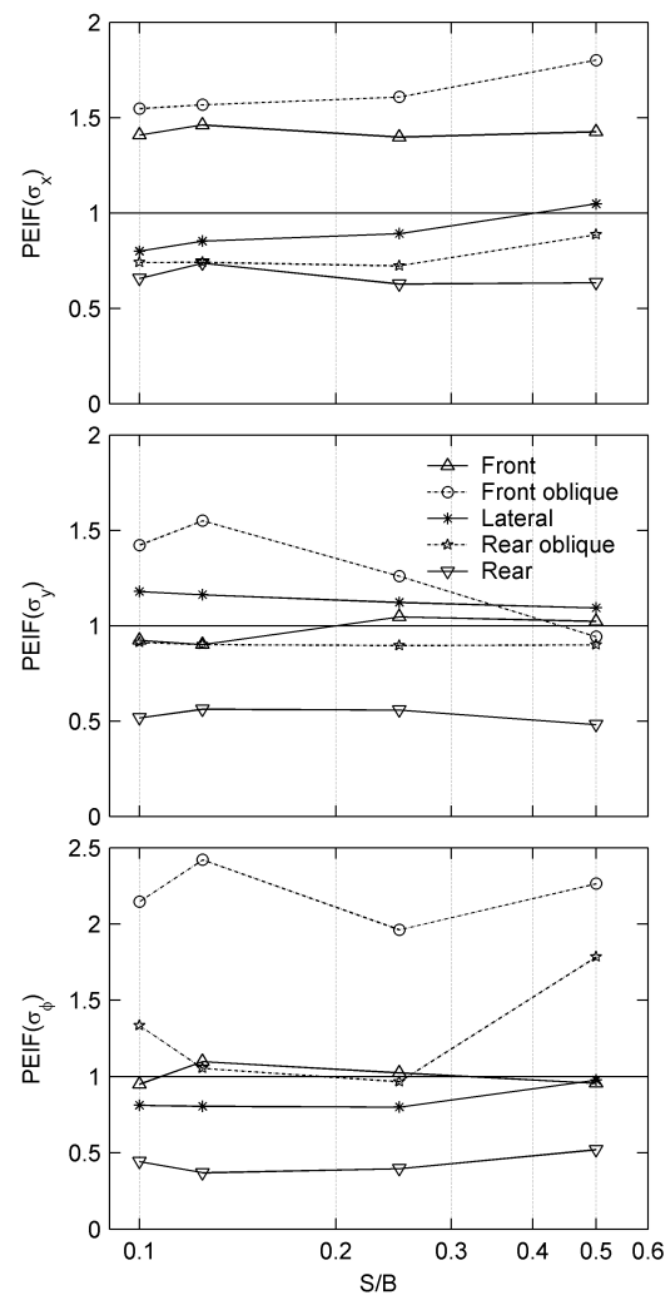

(b) Building $\mathrm{B}$
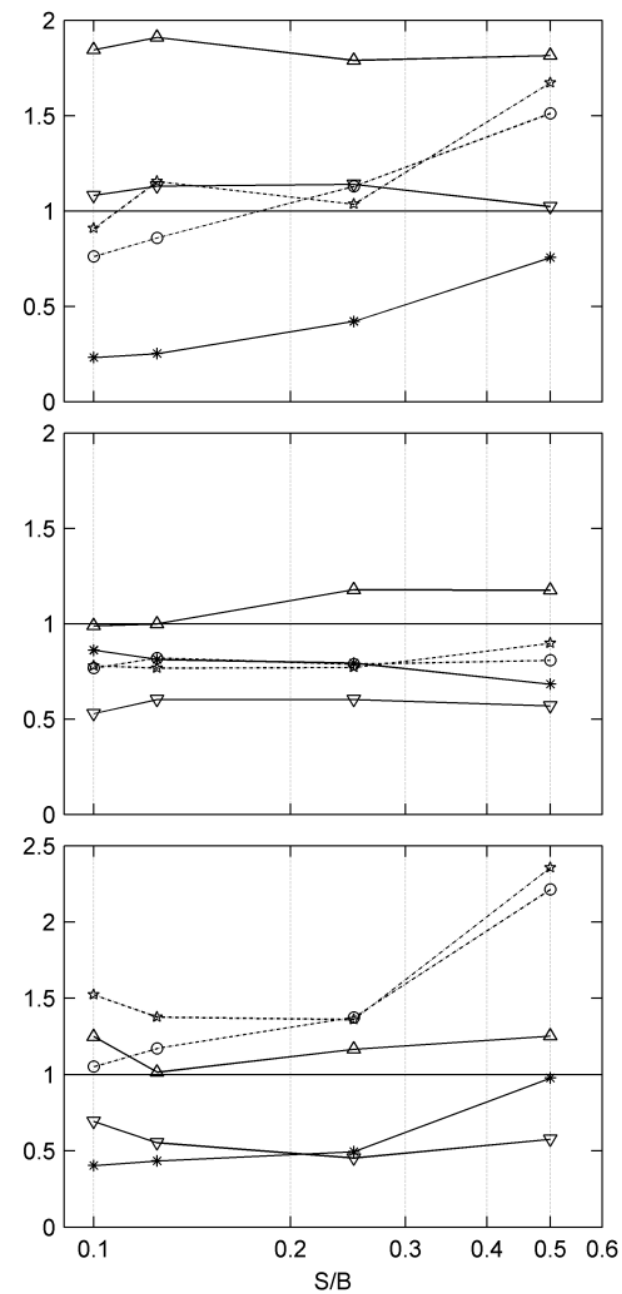

Fig. 4. Peak EIF within different wind incidence sectors: variation with building separation: (a) Building A; (b) Building B. 

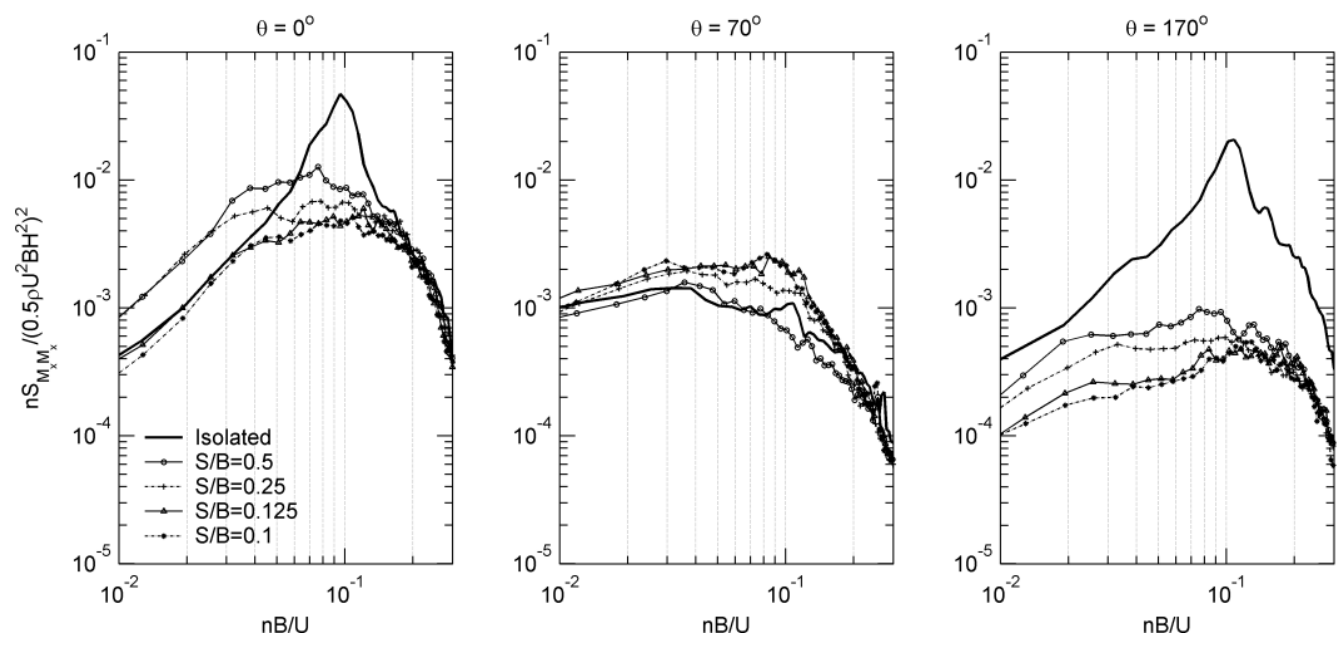

Fig. 5. Moment spectra of $M_{x}$ on Building A at $\theta$. (a) $0^{\circ}$; (b) $70^{\circ}$; (c) $170^{\circ}$. 
(a) Building F
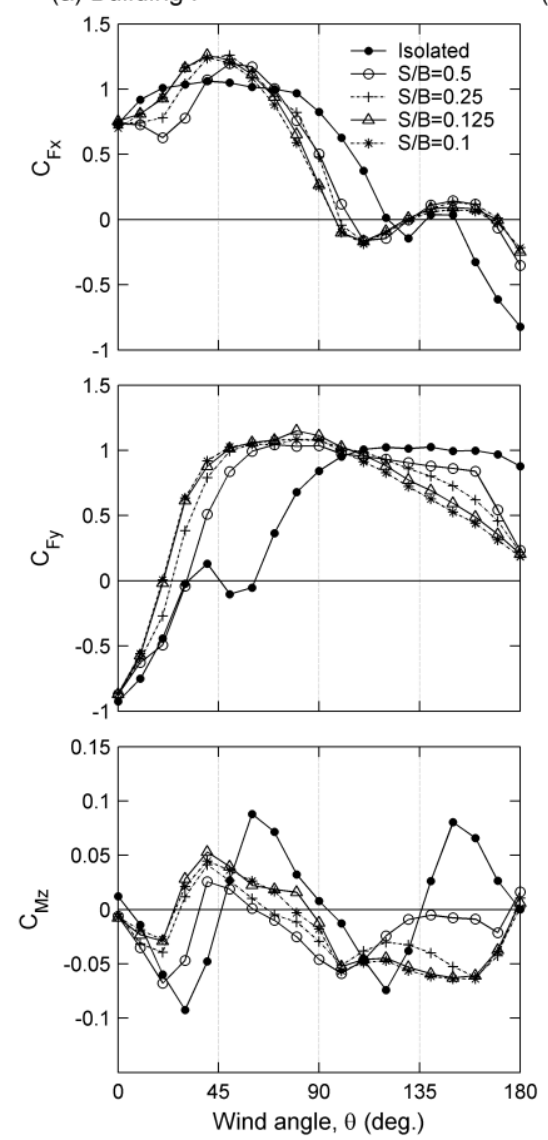

(b) Building G
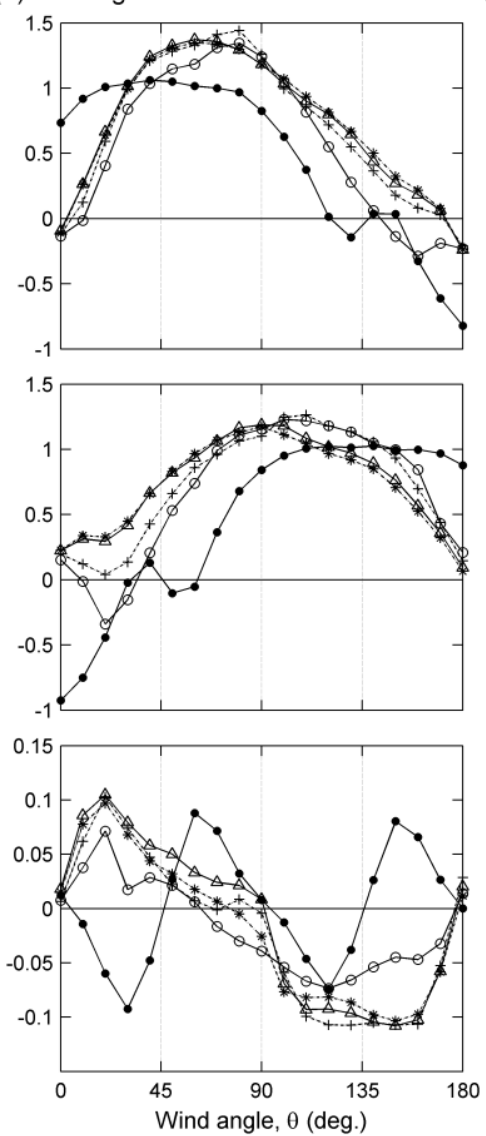

(c) Building $\mathrm{H}$
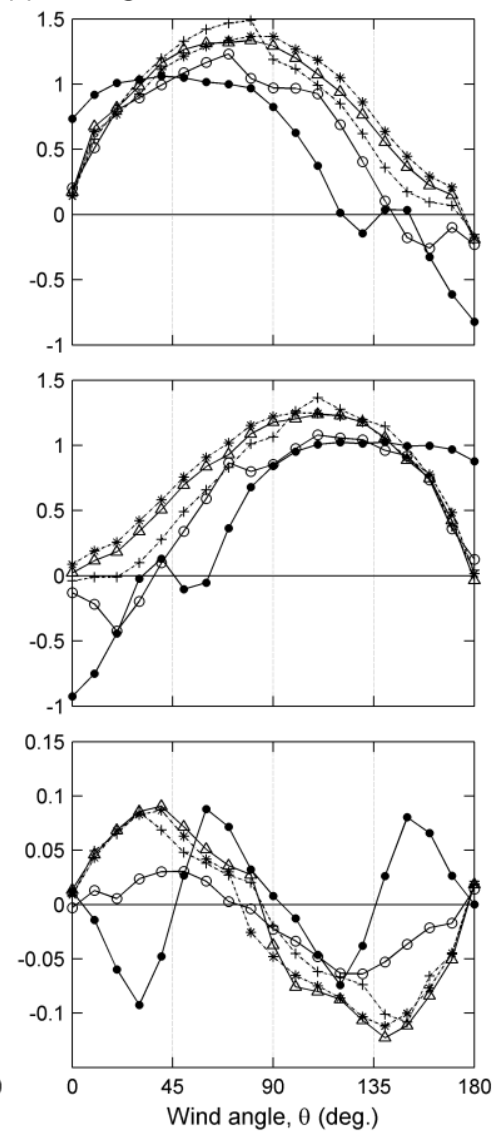

Fig. 6. Mean wind load coefficients: variation with wind angles and effects of building separation: (a) Building F; (b) Building G; (c) Building H. 

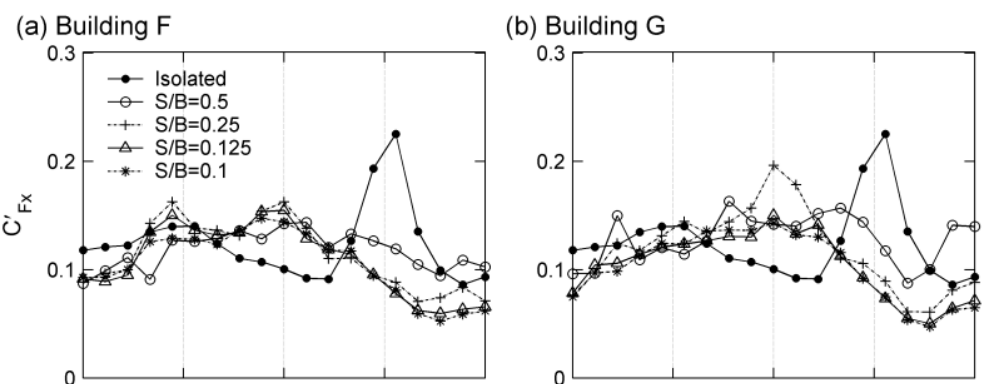

(c) Building $\mathrm{H}$
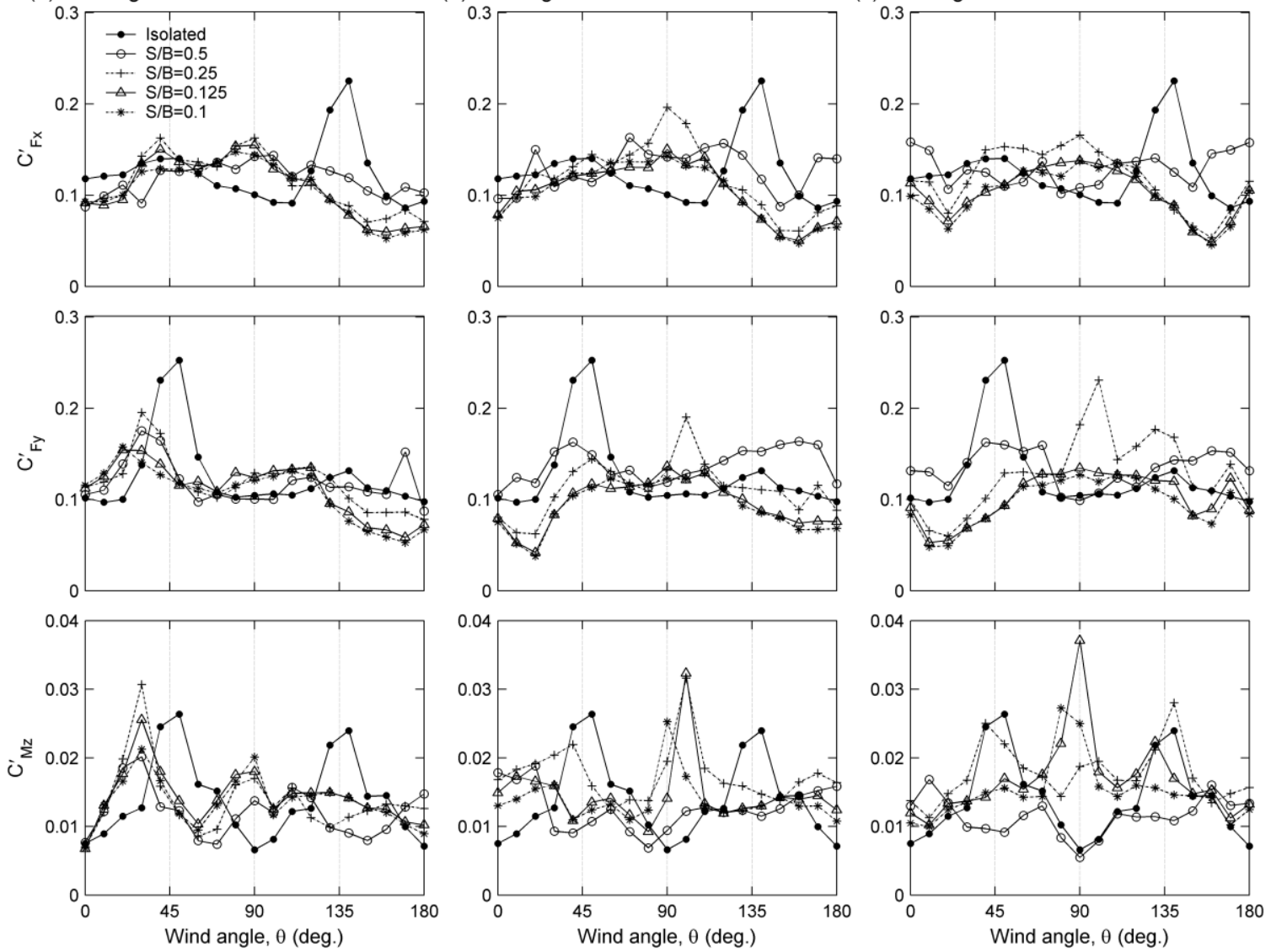

Fig. 7. Fluctuating wind excitation: r.m.s. wind load coefficients: (a) Building F; (b) Building G; (c) Building $\mathrm{H}$. 

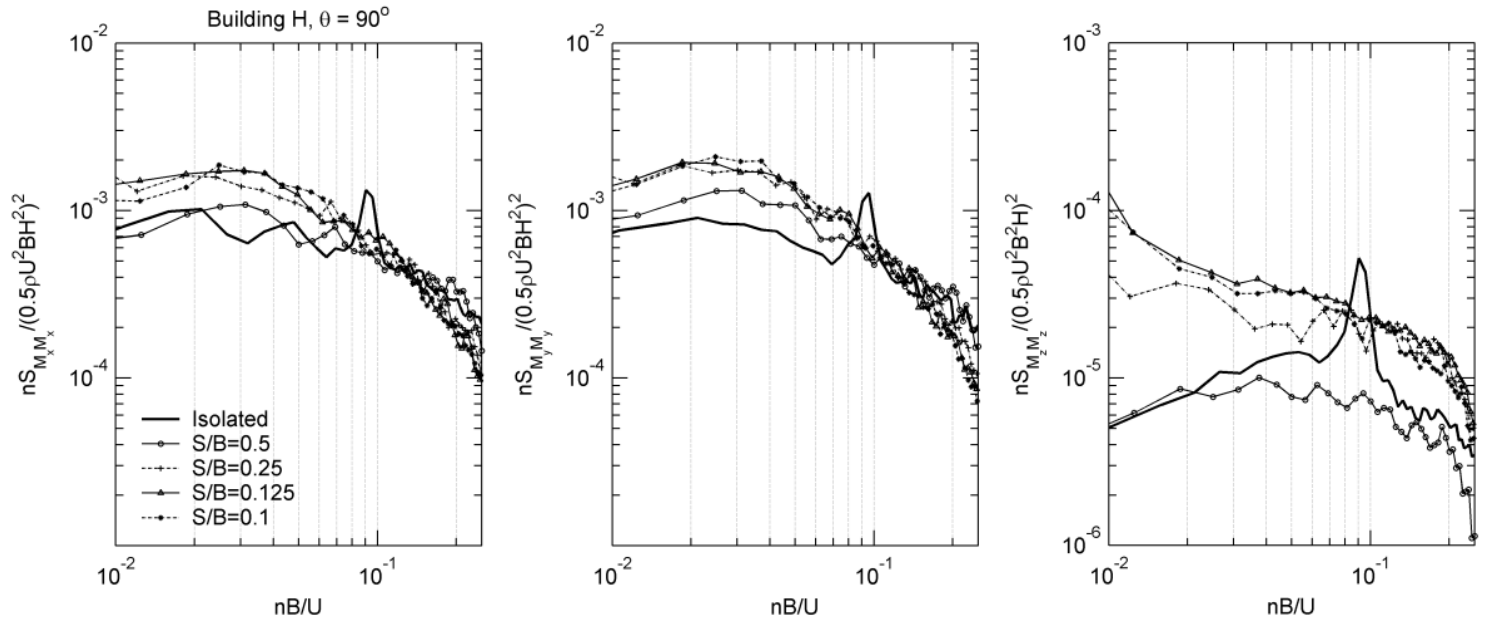

Fig. 8. Moment spectra on Building $\mathrm{H}$ at $\theta=90^{\circ}$. (a) $M_{x}$; (b) $M_{y}$; (c) $M_{z}$. 
(a) Building $\mathrm{F}$
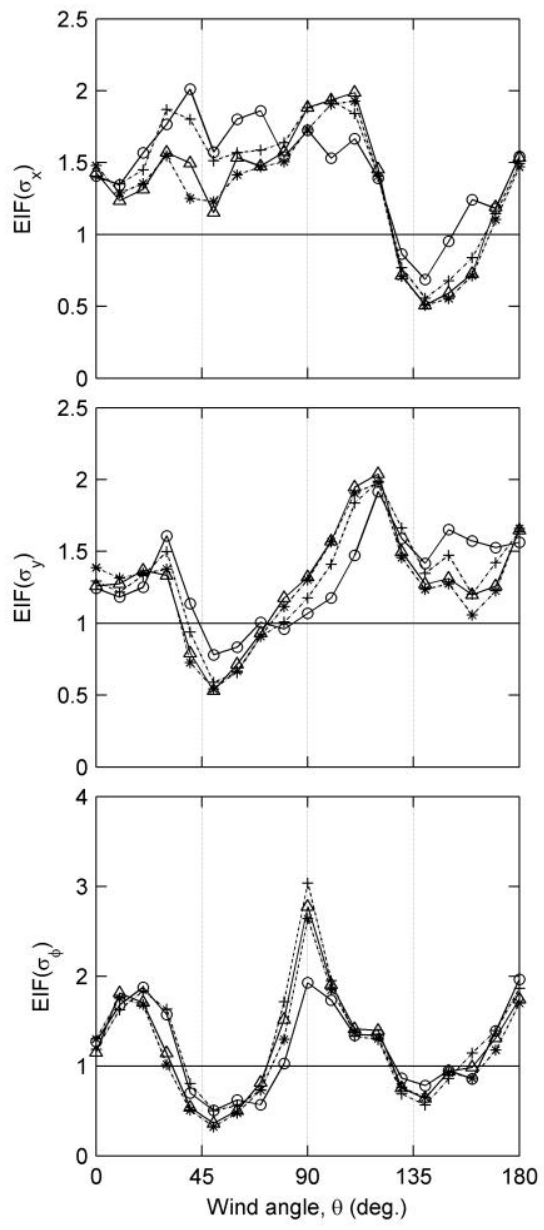

(b) Building G
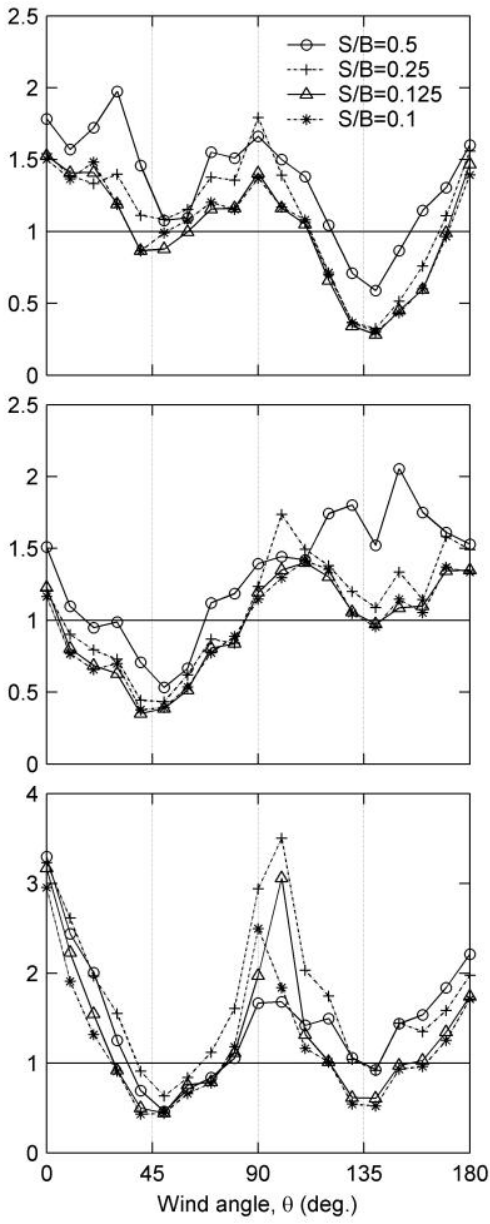

(c) Building $\mathrm{H}$
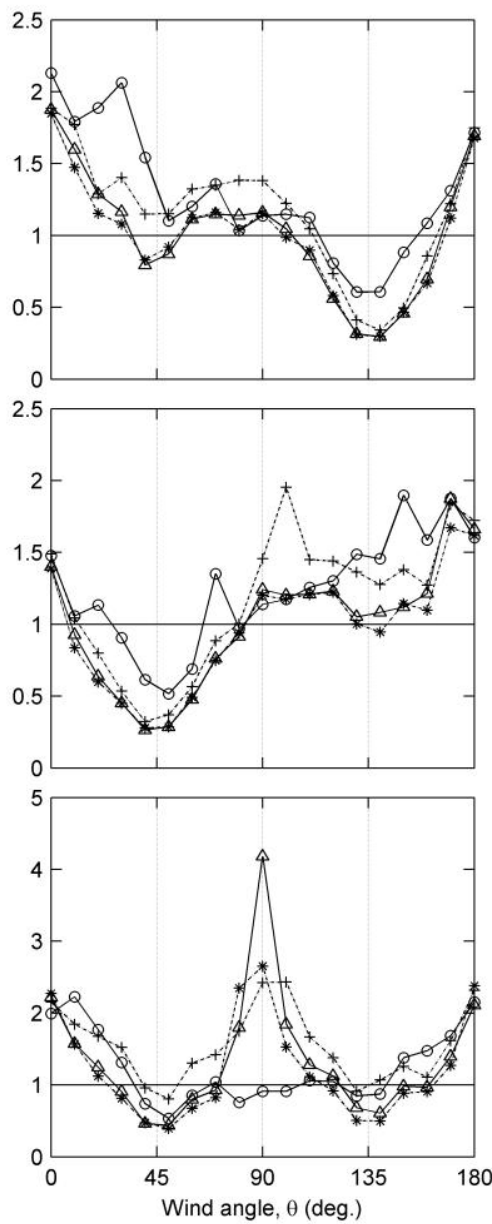

Fig. 9. Envelope interference factors (EIF) for the building row of the diamond pattern: (a)

Building F; (b) Building G; (c) Building H. 